\title{
A delimitação (quase) final da fronteira marítima no Mar de Timor
}

\author{
Ricardo Sousa da Cunha \\ Instituto Politécnico do Cávado e do Ave
}

\section{Introduçá̃o}

Timor-Leste e a Austrália chegaram, em 06 de março de 2018, a um acordo histórico sobre a delimitação da fronteira marííma no Mar de Timor, uma das mais antigas questões que tem ocupado o Direito Internacional no espaço da Lusofonia'. Ao longo dos anos, Portugal e Timor-Leste reclamaram a definição de uma linha mediana como critério para a delimitação fronteiriça, o que a Austrália recusou, durante anos, mesmo depois da entrada em vigor da Convenção das Nações Unidas sobre o Direito do Mar, invocando 0 prolongamento natural da sua plataforma continental. A Indonésia aceitou este como 0 critério de definiç̧ão da sua fronteira marítima com a Austrália e negociou um Acordo de exploração conjunta do Mar de Timor durante o período da ocupação, que despois da restauração da independência não foi aceite pelo estado de Timor-Leste na sucessão de Estados.

Depois da restauração da independência de Timor-Leste, em 20 de maio de 2002, no que se refere ao território do Estado de Timor-Leste, a Constituiçãa estabelece no seu art. 4. ${ }^{0}$ n. ${ }^{0} 1$ que: "O território da República Democrática de Timor-Leste compreende a superfície

\footnotetext{
I Sobre a posição portuguesa no exercício do Direito à autodeterminação do povo timorense vide MIGUEL Galvão Teles e Paulo Canelas de Castro, "Portugal and the right of peoples to self-determination" in Archiv des Völkerrechts, 34 (1), 2-46.
} 
ULP Law Review | Revista de Direito da ULP

Vol. 13, n. .1

doi: 10.46294/ulplr13n1d3

terrestre, a zona marítima e o espaço aéreo delimitados pelas fronteiras nacionais, que historicamente integram a parte oriental da ilha de Timor, o enclave de Oe-Cusse Ambeno, a ilha de Ataúro e o ilhéu de Jaco.". A delimitação das fronteiras marítimas é remetida pelo n. ${ }^{0} 2$ do art. 4. ${ }^{0}$ da CRDTL para a lei que "fixa e define a extensão e o limite das águas territoriais, da zona económica exclusiva e os direitos de Timor-Leste na zona contígua e plataforma continental', obrigaçãa essa que foi cumprida pela Lei n. ${ }^{\circ}$ 7/2002, de 20 de setembro (sobre fronteiras marítimas do território da República Democrática de Timor-Leste), adotada no exercício da competência legislativa exclusiva prevista no art. $95^{\circ}{ }^{\circ}$, n. ${ }^{\circ}$ 2, alínea b) da Constituição da República Democrática de Timor-Leste (CRDTL), seguindo muito de perto 0 disposto na Convenção das Nações Unidas sobre o Direito do Mar (UNCLOS ou CNUDM), além de recomendar a sua rápida ratificação (entretanto ocorrida em 08 de janeiro de 2013)2.

Historicamente, a definição costumeira da soberania sobre o espaço maríimo apontava para a fixação unilateral de acordo com a possibilidade de exercer a soberania sobre esse espaço. Por isso, o mais remoło critério de delimitação apontava para a possibilidade de exerćício de jurisdição de cada Estado segundo o critério do disparo de um tiro de canhão, que assim delimitou, durante vários anos, a jurisdição do Estado ao espaço marítimo de 3 milhas sobre 0 qual poderia, de facto, exercer a sua soberania ${ }^{3}$. Não sendo aceitável, quotidianamente, este critério, nem tecnicamente exequivel, e na falta de critérios universalmente aceites para 0 efeito, a polémica foi, durante muito tempo, resolvida pela jurisprudência dos tribunais e da arbitragem internacionais que apontou os critérios para a delimitação da soberania estadual sobre o espaço marítimo.

\footnotetext{
${ }^{2}$ Vide AAVV, Constituiç̃ão Anotada da República Democrática de Timorteste, (Braga, DH-Cll, Universidade do Minho, 2001), 28 e ss.

${ }^{3}$ Calculado por Ferdinand Galiami, com base no desenvolvimento de Bynkershoek do brocardo juŕdico "terrae potestas finitur ubi finitur armorum vis" a partir da ideia de Hugo Grotius de que todos os Estados podem exercer o controlo sobre o Mare Liberum a partir de terra. Vide NGuYen Quoc Dinh, Patrick Daller E ALLan Pellet, Droit International Public, (Paris, LGDJ, 7. ${ }^{0}$ Edição, 2002), 1165.
} 
ULP Law Review | Revista de Direito da ULP

Vol. 13, n. .1

doi: 10.46294/ulplr13n1d3

Já depois da primeira codificação do Direito do Mar, em 19584 , o direito à definição

unilateral das fronteiras marítimas foi aceite no caso Gulf du Maine $e^{5}, 0$ que não invalidou que se procurassem critérios para a delimitação em casos de reclamação soberana concorrente sobre o mesmo espaço marítimo, neste caso referidos a uma decisão ex aequo et bono. A equidade deixou de ser regra para passar a ser o objetivo a concretizar por diversos "fatores" com a Convenção das Nações Unidas sobre o Direito do Mar, assinada em Montego Bay, em $1982^{\circ}$. A equidistância é, assim, um critério na busca de melhor solução equitativa, como o Tribunal Internacional de Justiça (TIJ) reconheceu, em particular, a partir do caso Líbia vs Malta e tem ganho importância como ponto de partida para a consideração das diversas "circunstâncias especiais" que condicionam a decisão sobre determinado caso. É também a lição que se pode retirar das mais recentes decisões do TIJ sobre a delimitação de fronteiras marítimas, como seja no caso Jan Mayen ${ }^{10}$, e Qatar vs Bahrein $^{11}$ e, em especial, no caso arbitral Canada vs France ${ }^{12}$.

\footnotetext{
${ }^{4}$ Convenç̧óes de Genebra sobre o Direito do Mar, de 29 de abril de 1958, conhecidas como UNCLOS I, a saber: Convenção sobre o Mar Territorial e a Zona Contígua, entrada em vigor em 10 de setembro de 1964, Convenção sobre a Plataforma Continental, entrada em vigor em 10 de junho de 1964, Convenção sobre o Alto Mar, entrada em vigor em 10 de setembro de 1962, Convenção sobre Pesca e recursos Vivos no Alto Mar, entrada em vigor em 20 de março de 1966.

${ }^{5}$ Decisão do TIJ, de 12.10.1984, no caso Gulf of Maine, (Canada v. EUA), IJ Reports 1984, 305.

${ }^{6}$ A decisão segundo a equidade não facilitou que se aprofundassem os critérios de delimitaç̧̃o, não se podendo falar, nem antes nem depois da Convenção de 1958, de regras claras sobre esta matéria, referidas à equidistância ou a qualquer outra circunstância especial. No entanto, 0 TIJ reconheceu, ainda ao abrigo da Convenção de 1958 (Decisão do TIJ de 14.06.1993, Caso Jan Mayen, entre a Dinamarca e a Noruega, disponível em: http://www.ici-cii.org/docket/files/78/6743.pdf.) a existência de circunstância especiais como "circunstância suscetíveis de alterar 0 resultado produzido pela aplicação automática do princípio da equidistância".

${ }^{7}$ Que podem incluir diversos critérios, como a configuração geral da costa, a estrutura física e geológica, os recursos naturais das zonas da plataforma continental, a largura das fachadas marítimas respetivas dos Estados e a sua massa terrestre, a fronteira terrestre entre as partes e outras características especiais ou individuais. ${ }^{8}$ Nguven Quoc Dinh, Patrick Dalller e Alaal Pellet, Droit International Public, (Paris, LGDJ, 7. ${ }^{0}$ Edição, 2002), 1190.

${ }^{9}$ Decisão TIJ, de 03.06.1985, Caso da Plataforma Continental entre a Líbia Arab Jamahiriya e Malta, disponível em: htrp://www.ici- cii.org/docket/files/68/6415.pdf.

${ }^{10}$ Decisão do TIJ de 14.06.1993, Caso Jan Mayen, entre a Dinamarca e a Noruega, disponível em: hitp://www.ici-cii.org/docket/files/78/6743.pdf.

"Decisão do TIJ, de 16.03.2001, Caso da delimitação marítima e territorial entre 0 Qatar e 0 Bahrain, disponível em: htrp://www.icj- cii.org/docket/files/87/7027.pdf.

${ }^{12}$ Em especial, vide o voto de vencido de Prosper Weil na Decisão do TIJ, de 10.06.1992, Case of the delimitation of maritime areas between Canada and France, IJ Reports 1992, páginas 265-341.
} 
ULP Law Review | Revista de Direito da ULP

Vol. 13, n. .1

doi: 10.46294/ulplr13n1d3

\section{A delimitação fronteiriça marítima entre Timor-Leste e Austrália}

Pelo menos desde a década de 1960, que a delimitação das fronteiras marítimas entre Timor-Leste e a Austrália no Mar do Sul se afigurava problemática. A estas dificuldades não são, naturalmente, estranhas as riquezas naturais de minerais fósseis, entretanto aí descobertas. 0 Mar de Timor é a parcela de mar que separa a costa sul da ilha de Timor do litoral Nordeste da Austrália com uma largura de cerca de 250 milhas, na zona mais estreita, e, na sua banda mais larga, de 290 milhas marítimas ${ }^{13}$.

A realidade geográfica no Mar de Timor não facilita a delimitaçãa fronteiriça, uma vez que a plataforma continental do Mar de Timor apresenta traços de descontinuidade - uma depressão profunda (conhecida como o Timor Through), situada a uma distância que varia entre as 40 e as 70 milhas maríimas ao longo da costa da ilha de Timor, cuja existência dá origem a dois bordos exteriores da margem continental, um timorense e outro australiano. A posição Australiana pretendia, assim, desde meados do século passado, fazer valer a teoria segundo a qual existem duas placas continentais descontínuas, pelo que, na delimitaçãa das fronteiras maríitimas, pretendia o reconhecimento da sua jurisdição sobre o leito e o subsolo do mar de Timor até ao bordo exterior da sua margem continental, segundo o argumento de "prolongamento natural da plataforma continental", o qual dista mais de 200 milhas marítimas das linhas de base australianas que servem para calcular o mar territorial, bem além do critério da equidistância ou de qualquer reclamação soberana timorense, o que não deixaria de ser relevante num espaço cujo subsolo é rico em combustíveis fósseis. A posição assim invocada faz-se também valer de um critério de explorabilidade, juntamente com

\footnotetext{
${ }^{13} \mathrm{~A}$ delimitação frontal da fronteira marítima consideraraia, à partida, a linha costeira mais longa como critério, como parece ser a solução no caso de Libia vs. Malta e no mais recente Jan Mayen, que utiliza como critério as duas linhas de base mais extremas na delimitação da "linha de base". 0 ratio entre a Austrália e Timor seria neste caso de 22:1, o que sempre apontaria numa solução favorável a Timor-Leste. Vide Nuno SÉRGIO Marques Antunes, "Spatial Allocation of Continental Shelf Rights in the Timor Sea: Reflections on Maritime Delimitation and Joint Development" in Estudos de Direito Internacional Público, (Coimbra, Almedina, 2004), também disponível em https://www.laohamutuk.org/OilWeb/RDTLdocs/TSO_FS/web/nunoarticle13-13.pdf, 28.
} 
ULP Law Review | Revista de Direito da ULP

Vol. 13, n. .1

doi: 10.46294/ulplr13n1d3

outras considerações, invocado na decisão do TIJ no caso North Sea Continetal Shelf $f^{4}$. Este foi, aliás, o critério invocado e, em larga medida, aceite na delimitação de fronteiras entre a Austrália e a Indonésia em $1972^{15}$. Na delimitação de fronteiras maríimas com a Indonésia, em dois tratados de maio de 1971 e de outubro de 1972, fixaram-se as fronteiras maríitimas entre os dois países numa zona intermédia entre 0 bordo exterior da margem continental australiana e a linha mediana.

Portugal sempre recusou, em nome de Timor-Leste, esta teoria para a delimitação de fronteiras maríimas no Mar Territorial de Timor, assim gerando um espaço na delimitação fronteiriça marítima conhecido como o Timor Gap (uma vez que toda a demais delimitação das fronteiras marítimas australianas, com a Indonésia, ficou definida em 1972). Portugal valia-se, já na altura, do argumento da equidistância, já previsível, pelo menos desde 1970, como critério mais relevante no direito internacional, a consagrar nas discussões em torno do que veio a ser a CNUDM, a partir da argumentação expendida, em especial, pelas partes no caso da North Sea Continetal Shelf $f^{6}$. Assim, Portugal concessionou à "PetroTimor" a prospeção e exploração de recursos no subsolo marítimo do Mar de Timor numa área fora da previsão Australiana. As pretensões portuguesas, na qualidade de potência administrante do território de Timor-Leste na falta do adequado exerć́cio do direito à autodeterminação pelo povo timorense, conduziram à apresentação de diversas formas de protesto ao governo australiano ${ }^{17}$.

A invasão e posterior integração de Timor na República Indonésia apenas foi reconhecida pela Austrália e a partir de 1978 foram conduzidas negociações entre os dois Estados no sentido de concluir um Tratado relativo à delimitação da fronteira marítima no que se

\footnotetext{
${ }^{14}$ Decisão do TIJ, de 20.02.1969, Caso da Plataforma Continental do Mar do Norte, entre a RFA/Holanda e Dinamarca, disponível em: http://www.ici-cii.org/docket/files/51/5535.pdf.

${ }^{15}$ As razões que levaram a Indonésia a aceitar esta delimitação, francamente prejudicial das suas fronteiras maríitimas com a Austrália não são objeto de análise aqui, mas não deixará de ser compreensível a necessidade de reconhecimento internacional e regional em especial do regime, então, recém-instalado em Jakarta Agreement between the Government of the Commonwealth of Australia and the Government of the Republic of Indonesia Establishing Certain Seabed Boundaries, de 18 de maio de 1971, disponivel em: http://www.un.org/Depts/los/LEGISLATIONANDTREATIES/PDFFILES/TREATIES/ AUS-IDN197ISB.pdf.

${ }^{16}$ Decisão do TIJ, de 20.02.1969, Caso da Plataforma Continental do Mar do Norte, entre a RFA/Holanda e Dinamarca, disponível em: http://www.ici-cii.org/docket/files/51/5535.pdf.

${ }^{17}$ Memorial of the Government of the Portuguese Republic, 18 de novembro de 1991, disponivel em https://www.icj-cii.org/files/case-related/84/6834.pdf.
} 
ULP Law Review | Revista de Direito da ULP

Vol. 13, n. .1

doi: 10.46294/ulplr13n1d3

remanescia do segmento do "Timor Gap". 0 início formal das negociações marcou, em 1979, o reconhecimento jurídico da anexação indonésia de Timor-Leste. A Austrália e Indonésia, em 11 de dezembro de 1989, celebraram o "Timor Gap Treaty" no qual se estabelecia uma zona conjunta de exploração dos recursos do Mar de Timor e, na delimitaçãa da plataforma continental, segundo um complexo sistema que, nos seus diversos limites, combinava linhas de equidistância, critérios de prolongamento natural (Timor Trough) e critérios mistos.

Em qualquer caso, ressuscitava-se 0 critério de explorabilidade do caso North Sea Continental Shelf ${ }^{8}$, já afastado pela CNUDM, tanto quanto pela jurisprudência do TIJ, nomeadamente, no caso Libia/Malta ${ }^{19}$. Mais uma vez, as considerações de realpolitik pareciam ter garantido a exploração dos importantes recursos no subsolo do Mar de Timor, ao mesmo tempo que garantiam à Indonésia, potência ocupante em Timor-Leste, 0 reconhecimento da soberania sobre Timor-Leste pelo mais importante vizinho na região. Portugal, enquanto potência administrante do território de Timor-Leste, saído de um processo de descolonização e em vias de exercer o seu Direito à autodeterminação, como reconhecido pela ONU, opôs-se à celebração deste Tratado junto do TIJ.

Neste caso, Portugal apresentou, em fevereiro de 1991, petição ao $\mathrm{TIJ}^{20}$ argumentando que a Austrália havia violado os direitos do povo de Timor-Leste à autodeterminação e violado os direitos de Portugal como potência administrante, com a conclusão do Tratado pelo qual se estabelecia a zona de cooperação entre a Austrália e a Indonésia sobre o Mar de Timor. A Indonésia não foi demandada por não se encontrar sujeita à jurisdição do TIJ. Assim, requeria-se que 0 Tribunal declarasse:

1. o direito do povo de Timor Leste à autodeterminação, à integridade territorial e à soberania permanente sobre os seus recursos naturais;

2. a oponibilidade, em relação à Austrália, das obrigações, poderes e direitos de Portugal, enquanto potência administrante de Timor Leste;

\footnotetext{
${ }^{18}$ Decisão do TIJ, de 20.02.1969, Caso da Plataforma Continental do Mar do Norte, entre a RFA/Holanda e Dinamarca, disponivel em: http://www.icj-cii.org/docket/files/51/5535.pdf.

${ }^{19}$ Decisão TIJ, de 03.06.1985, Caso da Plataforma Continental entre a Líbia Arab Jamahiriya e Malta, disponivel em: http://www.ici- cii.org/docket/files/68/6415.pdf.

${ }^{20}$ Disponível em https://www.ici-cii.org/en/case/84/written-proceedings.
} 
ULP Law Review | Revista de Direito da ULP

Vol. 13, n. .1

doi: 10.46294/ulplr13n1d3

3. 0 incumprimento australiano da obrigação de negociar com Portugal em todas as matérias relativas à plataforma continental de Timor Leste;

4. o desrespeito australiano pelas resoluções do Conselho de Segurança relativas a Timor Leste;

5. como ilícito o comportamento da Austrália e, por fim,

6. que, até ao momento em que 0 povo timorense pudesse exercer 0 seu direito à autodeterminaç̧ão, a Austrália fosse aconselhada a renunciar a qualquer negociaçãa, assinatura, ratificaçãa ou execuçãa de acordos com países terceiros, relativos à delimitação ou exploração da plataforma continental de Timor Leste.

Na decisão sobre os méritos, em 30 de junho de 1995²1, o Tribunal Internacional de Justiça veio reconhecer a existência de uma disputa entre Portugal e a Austrália, acabando, no entanto, por decidir não poder exercer a sua jurisdição sobre a questão apresentada, uma vez que isso impunha a anterior pronúncia sobre o poder de Portugal ou da Indonésia de celebrar Tratados em nome de Timor-Leste. A Indonésia não podia ser demandada, uma vez que não era parte nesta ação por não reconhecer a jurisdição compulsória do Tribunal, ao abrigo do art. 36. ${ }^{\circ}$ do seu Estatuto. 0 Tribunal reconheceu expressamente que as partes reconheciam Timor Leste como um território não autónomo e que o seu povo tinha 0 direito à autodeterminação. Decidiu também a natureza erga omnes, oponível a todos os sujeitos de Direito Internacional, do Direito à autodeterminação dos povos, tal como consagrado na Carta das Nações Unidas e reconhecido pelo Tribunal. Declarou mesmo tratar-se de um "princípio essencial de Direito Internacional contemporâneo".

\subsection{A Declaração da restauração da independência}

0 exerćício da autodeterminação timorense, através do referendo em 1999, seguido da declaração da restauração da independência em 20 de maio de 2002 não reconheceu a sucessão de Timor-Leste em qualquer das obrigações da Indonésia. 0 novo Estado, na

\footnotetext{
${ }^{21}$ Disponível em https://www.ici-cii.org/files/case-related/84/084-19950630-JUD-01-00-EN.pdf.
} 
ULP Law Review | Revista de Direito da ULP

Vol. 13, n. .1

doi: 10.46294/ulplr13n1d3

sucessão dos Tratados, fez-se valer do princípio da tabula rasa em matéria de regime de sucessão de Estados em Direito Internacional ${ }^{22}$ pelo que Timor-Leste não sucedeu à Indonésia no Tratado celebrado entre a Indonésia, em nome de Timor-Leste, e a Austrália para delimitação de fronteiras maríitimas em 11 de dezembro de 1989 (Tratado do Timor-Gap). Nos termos do art. 151. ${ }^{0}$ da Constituição timorense, expressamente, se prevê que a sucessão do Estado de Timor-Leste nos compromissos em seu nome assumidos anteriormente será definida caso a caso, fazendo-se referência especial àqueles relativos à exploração de recursos naturais. Assim, em 05 de julho de 2001, antes da declaraçã̃o de restauração da independência, Timor-Leste e a Austrália celebraram um Memorandum of Understanding (MOU) pelo qual aceitaram a exploração conjunta de JDPA (joint development petroleum area) com receitas partilhadas, sem prejuízo para as reclamações de ambas as partes. 0 MOU de 2001 conduziu à celebração do Tratado do Mar de Timor em 2002, por troca de cartas diplomáticas, que não entrou em vigor imediatamente pendente das negociaçães relativas a outros campos de exploração. № entanto, pelo mesmo meio, foram tomadas medidas no sentido de aplicar algumas disposições do MOU, em particular relativo a partilha de receitas de explorações já existentes.

A recusa de vinculação ao Tratado do Timor-Gap ficou estabelecida em instrumento de troca de notas diplomáticas entre Timor-Leste e a Austrália, que acompanha o Tratado do Mar de Timor entre Timor-Leste e Austrália, de 20 de maio de 2002, ratificado pela Resolução do Parlamento Nacional n. ${ }^{\circ}$ 2/2003, de 1 de abril. Mesmo 0 acordo celebrado entre a UNTAET - United Nations Transitional Authority in East Timor - e a Austrália relativamente à repartição dos recursos caducou com a declaraçã̃o de restauração da independência. Nenhuma destas disposições resolveu a questão da delimitação das fronteiras maríitimas. Assim, sem prejuízo para os acordos de Direito Internacional, a Lei n. ${ }^{0}$ 7/2002, de 20 de setembro, reclama para Timor-Leste 200 milhas de plataforma continental e Zona Económica Especial, de todo irreconciliável com a posição australiana,

\footnotetext{
${ }^{22}$ Nguven Quoc Dinh, Patrick Dallier e Alain Pellet, Droit International Public, (Paris, LGDJ, 7. ${ }^{a}$ Edição, 2002), 550 e ss.
} 
ULP Law Review | Revista de Direito da ULP

Vol. 13, n. .1

doi: 10.46294/ulplr13n 1d3

remetendo a delimitação para as regras internacionais, nomeadamente considerando a CNUDM.

A Austrália, entretanto, retirou-se da jurisdição do Tribunal Internacional de Justiça e do Tribunal Internacional do Direito do Mar relativamente à delimitação de fronteiras marítimas, em 21 de março de 2002, poucos dias antes da declaração da restauração da independência em 20 de maio de 2002, pelo que se tornou muito difícil a Timor-Leste exigir judicialmente a justeza da sua posição. Este comportamento parece ostensivamente dirigido a impossibilitar o uso por parte de Timor-Leste dos mecanismos jurisdicionais previstos internacionalmente, o que, foi recusado pelo TIJ no caso Nicaráguad $a^{23}$. Neste caso, os EUA retiraram-se da mesma jurisdiççoo voluntária do TIJ para evitar que a Nicarágua fizesse uso desse mecanismo processual, apesar de 0 terem feito numa fase mais processual avançada, depois de formalmente notificados desta intenção. Por isso, considerando a jurisprudência afirmada pelo Tribunal Internacional de Justiça no caso da renúncia norte-americana à jurisdição facultativa do TII com efeitos a produzirem-se num caso concreto, poder-se-ia na ocasiẫo ter discutida da legalidade da renúncia australiana à jurisdição do TIJ, que parece, claramente, orientada a evitar o exerćcicio do direito de acesso ao direito internacional pelo Estado de Timor-Leste ${ }^{24}$. A falta de limite temporal ao exerććcio deste direito autorizaria ainda a ponderação deste passo numa fase posterior do processo.

\subsection{A Exploração Conjunta}

Na falta de acordo quanto à delimitação das fronteiras marítimas, as partes devem exercer o dever de coibição na exploraçã̃o dos recursos naturais, sem prejuízo de, nos termos do art. 83. ${ }^{\circ}$ da CNUDM, se procuraraem soluçōes que permitissem o desenvolvimento conjunto. Foi o que aconteceu entre Timor-Leste e a Austrália, com a JPDA, em especial, considerando a impossibilidade (ou dificuldade) de sujeitar a questão ao TIJ ou outro meio

\footnotetext{
${ }^{23}$ Decisão do TIJ, de 10.05.1984, Caso Military and Paramilitary Activities in and against Nicaragua (Nicaragua. v. U.S.), disponível em htrp://www.worldcourts.com/ic//eng/decisions/1984.05.10_military_paramilitary.htm.

${ }^{24}$ Neste sentido vide Vaughan Lowe, Christopher Carleton E Christopher Ward, "Sobre as fronteiras maritimas de Timor-Leste", abril de 2002, disponivel em http://www.petrotimor.com/img/glopPT.pdf, 22 e ss.
} 
ULP Law Review | Revista de Direito da ULP

Vol. 13, n. .1

doi: 10.46294/ulplr13n 1d3

jurisdicional. De alguma forma, esta soluçãa apontava os termos (à ocasião) de uma previsível solução para a delimitação de fronteiras marítimas entre Timor-Leste e a Austrália, mas não poderia criar a favor da parte timorense qualquer direito ou expectativa juridicamente tutelada, nem a favor da parte Australiana qualquer costume, que obstasse à futura delimitação de fronteiras. Da mesma forma, desta circunstância não se pode extrair 0 reconhecimento de qualquer direito para qualquer das partes (p. ex. da distribuição através de um gasoduto para Darwin). Por tudo o que vai referido, Timor-Leste manteve a intenção de pressionar a Austrália para avançar com a delimitação final das fronteiras maŕíimas, a única capaz de definitivamente resolver a questão aqui suscitada.

0 regime da Exploraçãão Conjunta é uma das formas de exercício de direitos soberanos sobre área disputada, definindo área, soberania sobre os recursos naturais, quadro legal e de jurisdição, bem como termos e condiç̧̄es de exerćício. Quanto à delimitação fronteiriça, 0 argumento australiano, valendo-se da realidade geomorfológica, não parecia, já nessa altura ter acolhimento jus-internacional, nem sequer sendo oponível a Timor-Leste o facto de a Indonésia o ter aceite, uma vez que sempre Portugal e Timor-Leste recusaram essa posição, agora universalmente recusada, inclusivamente, no caso Libia v. Maltta ${ }^{25}$. Além disso, a veracidade desse argumento foi mesmo posta em causa em estudos mais recentes, que parecem inclusivamente apontar apara a inexistência de uma tão marcante falha geomorfológica ${ }^{26}$ - 0 que, aliás, poderia fundamentar a invocação por parte da Indonésia da cláusula rebus sic stantibus para a delimitação acordada com a Austrália em 1972. Além disso, a macrogeográfica aponta o facto de nunca Timor-Leste, em nenhuma das suas linhas de base poder exercer jurisdição sobre 200 milhas de plataforma continental, um fator que deverá ser ponderado a seu favor, tal como o TIJ fez no caso Guiné vs GuinéBissaư?

\footnotetext{
${ }^{25}$ Decisão TIJ, de 03.06.1985, Caso da Plataforma Continental entre a Líbia Arab Jamahiriya e Malta, disponível em: htrp://www.ici- cii.org/docket/files/68/6415.pdf.

${ }^{26}$ JoachIM F. GENRICH, "Accretion of the Southern Banda Arc to the Australian Plate Margin Determined by Global Positioning System Measurements" in 15(2) Tectonics 288, página 293 apud Nuno Sérglo Maroues Antunes, "Spatial Allocation of Continentral Shelf Rights in the Timor Sea: Reflections on Maritime Delimitation and Joint Development" in Estudos de Direito Internacional Público, (Coimbra, Almedina, 2004), também disponível em https://www.laohamutuk.org/OilWeb/RDTLdocs/TSO_FS/web/nunoarticle13-13.pdf, 28.

${ }^{27}$ Decisão Arbitral, de 14.02.1985, Caso da delimitação da fronteira marítima entre a Guiné e a Guiné-Bissau, disponível em http://digitalcommons.law.umaryland.edu/cgi/viewcontent.cgi? $?$ article $=1400 \&$ context $=$ mijl.
} 
ULP Law Review | Revista de Direito da ULP

Vol. 13, n. .1

doi: 10.46294/ulplr13n1d3

№ Mar de Timor, sucederam-se os acordos dirigidos a garantir a explorabilidade dos recursos minerais do Mar de Timor, que consagravam diferentes moratórias relativamente à definiç̧ão final das fronteiras marítimas entre Timor-Leste e a Austrália.

0 Tratado entre o Governo da República Democrática de Timor-Leste e o Governo da Austrália sobre Determinados Ajustes Marítimos no Mar de Timor e Acordo Transitório quanto à vigência do Tratado do Mar de Timor (CMATS, segundo a sua designação mais corrente em língua inglesa) foi assinado em 12 de janeiro de 2006. Em Timor-Leste, 0 processo de ratificaçã̃o foi concluído pela Resolução do Parlamento Nacional n. ${ }^{0}$ 4/2007, de 8 de março. Na Austrália foi invocada a "exceção de interesse nacional", em 22 de fevereiro de 2007, para garantir a sua entrada em vigor sem o competente processo parlamentar, que seria mais demorado.

Este Acordo, juntamente com o Acordo de Unitização dos Campos do Greater Sunrise, visava permitir a exploração destes campos petrolíferos, que se encontravam fora da Área de Exploração Petrolifera Conjunta (JPDA, segundo a sua designação mais corrente em língua inglesa) do Tratado do Mar de Timor, de 2002. 0 CMATS garantiu para isso condições mais favoráveis a Timor-Leste do que aquelas que resultavam do Tratado do Mar de Timor (TMT). Na JPDA, que inclui os campos atualmente em exploração, a repartiçãa das receitas é de 90\% (TL) - 10\% (AUST). Considerando a parte dos campos Greater Sunrise, apenas parcialmente dentro da JPDA, o valor total nos campos do Greater Sunrise seria 18\% (TL) 82\% (AUST), e com o CMATS passou a ser 50\% - 50\%. 0 CMATS incluía também uma moratória sobre a questão da delimitação fronteiriça maríitima pelo período de 50 anos, no art. $4 .{ }^{0}$, n. ${ }^{0} 1.0$ resultado destas negociações foi um equilíbrio difíicil entre os interesses dos Estados. Timor-Leste precisaria do TMT em 2002 para avançar com a exploraçãa dos campos da Bayu-Undan que garantisse recursos a um jovem país pobre, mas a Austrália recusou ratificar 0 TMT até que Timor-Leste assinasse a Acordo de Unitização, em 2003, e TimorLeste recusou-se a ratificar a Acordo de Unitização, que considerava ter sido assinado sob coação, até chegar ao acordo CMATS, quatro anos mais tarde. 0 CMATS foi, por isso, uma solução de compromisso que permitiu a exploração dos recursos minerais do Mar de Timor, considerando a dificuldade de delimitação das fronteiras maríitimas entre Timor-Leste, a 
ULP Law Review | Revista de Direito da ULP

Vol. 13, n. .1

doi: 10.46294/ulplr13n1d3

Austrália e a Indonésia, desde o tempo da colonização Portuguesa, mas não excluía o dever de negociar, de boa-fé, definitivamente as fronteiras marítimas.

0 CMATS foi regularmente assinado e ratificado pelo Estado Timorense, pelo Governo, cujo Primeiro-Ministro era Mari Alkatiri, assinado pelo Ministro dos Negócios Estrangeiros e Cooperação José Ramos-Horta, e mandado publicar pelo Presidente da República Xanana Gusmão. 0 CMATS manteve em vigor os contratos celebrados em 2003 entre Timor-Leste e a Austrália e as operadoras petrolíferas (Woodside, Shell, ConocoPhilips e a Osaka Oi). Na ocasião, havia a expectativa de uma rápida exploração dos campos do Greater Sunrise, que não ocorreu, em parte devido à divergência entre Timor-Leste, Austrália e os operadores acerca da instalação da refinaria, com a Austrália a preferir a solução Darwin, Timor-Leste a preferir a solução da sua costa Sul (Beaçu) e as operadoras a defenderem uma solução de alto-mar (off-shore).

Na falta de uma solução, o próprio CMATS previa que a falta de exploração no prazo de seis anos autorizaria qualquer Estado a denunciar o Tratado (art. 12.2 a.), mas que no caso de existir futura exploração se manteriam as percentagens de repartição de 50\% - 50\% (art. 12.3). A partir de fevereiro de 2013 passou, por isso, a discutir-se as implicações da denúncia unilateral por parte de qualquer dos signatários do CMATS, considerando a sua não implementação. A Timor-Leste esta solução não alteraria 0 essencial da repartição de recursos (50-50) pelo que procurou, desde 2013, anular o CMATS com base na negociação sob máffé do CMATS.

Em primeiro lugar foi tentada a via negocial, depois a via arbitral prevista no Anexo B do Tratado do Mar de Timor. Timor-Leste invocava a má-fé negocial, em especial, a realização de escutas e outras formas de espionagem aos negociadores timorenses, em 2004, aquando das respetivas negociações. Não é claro que a espionagem constitua um vício na negociação de Tratados de Direito Internacional, nem que tenha como consequência a invalidade dos Tratados, uma vez que apenas normas de valor reforçado (ius cogens) terão essa consequência nos termos do art. 53. ${ }^{\circ}$ do Estatuto do Tribunal Internacional de Justiça. Da mesma forma, vários titulares de órgãos de soberania timorenses reconheceram saber da espionagem e esse facto não condicionou a assinatura do CMATS ou do TMT, pelo que não 
ULP Law Review | Revista de Direito da ULP

Vol. 13, n. .1

doi: 10.46294/ulplr13n1d3

impediu a perfeita formação da vontade do Estado de Timor-Leste na assinatura deste Tratado. Paralelamente, decorreu no Tribunal Internacional de Justiça um processo cautelar quando a Austrália atacou os escritórios de advogados australianos que patrocinavam a causa timorense, tendo sido obrigada a devolver todos os documentos e a abster-se de tais condutas. Em 11 de abril de 2016, Timor-Leste anunciou 0 início de um processo de Conciliação Obrigatório ao abrigo da CNUDM, com o objetivo de "concluir um acordo com a Austrália sobre Fronteiras marítimas permanentes". A Austrália opôs-se à jurisdição do Tribunal e à admissibilidade do meio usado por Timor-Leste ${ }^{28}$, mas depois da afirmação da jurisdição do Tribunal ${ }^{29}$, foram conduzidas várias rondas negociais com vista à obtençã̃o de um acordo que nem sempre pareceu possível.

Finalmente, no final de 2016, foi anunciado um Acordo para a denúncia do CMATS, unilateral de Timor-Leste, mas de acordo com a Austrália, alcançado com vista a fomentar a confiança entre as partes para conduzir as negociações dirigidas à delimitação fronteiriça definitiva e subsequente exploração dos recursos minerais no Mar de Timor. Assim, afirmavase que "A fim de evitar incertezas, os Governos de Timor-Leste e da Austrália vêm declarar o seu entendimento comum sobre os efeitos jurídicos do termo do Tratado sobre Determinados Ajustes Marítimos no Mar de Timor, que é o seguinte:

- Os Governos de Timor-Leste e da Austrália concordam que, na sequência do termo do Tratado sobre Determinados Ajustes Marítimos no Mar de Timor, mantém-se em vigor entre eles, na sua forma original, isto é, antes da sua alteração pelo Tratado sobre Determinados Ajustes Marítimos no Mar de Timor, o Tratado do Mar de Timor entre o

\footnotetext{
${ }^{28}$ A Austrália apresentou seis objeções à competência da Comissão: (1) a moratória prevista no art. $4^{0}$ do Tratado CMATS impediria 0 recurso à conciliação obrigatória no âmbito da UNCLOS; (2) o Tratado CMATS, incluindo a moratória é uma medida provisória; (3) a troca de cartas entre as partes (isoladamente ou em conjunto com a (MATS) é um acordo na aceção do art. 281. ${ }^{\circ}$ da UNCLOS para prosseguir com a resolução deste litígio através de negociações; (4) o litígio entre as partes surgiv em 2002 e não após a entrada em vigor da UNCLOS para TL; (5) uma vez que as partes não haviam iniciado negociações sobre a delimitação e, portanto, a conciliação compulsória nos termos do Artigo 298. não pode ser acionada; e (6) 0 litígio é inadmissível porque viola as obrigações de Timor-Leste no âmbito do CMATS.

${ }^{29}$ Decisão do TPA, de 19 de setembro de 2016, no PCA Case n. ${ }^{0}$ 2016-10, A Conciliation Commission constituted under Annex V to the 1982 United Nations Convention on the Law of the Sea between The Democratic Republic of Timor-Leste and The Commonwealth of Australia, disponivel em https://pcacases.com/web/sendAttach/1921.
} 
ULP Law Review | Revista de Direito da ULP

Vol. 13, n. .1

doi: 10.46294/ulplr13n 1d3

Governo de Timor-Leste e o Governo da Austrália de 20 de maio de 2002, bem como o seu quadro regulamentar de apoio.

- Os Governos de Timor-Leste e da Austrália concordam que a cessacẵo do Tratado sobre Determinados Aiustes Marítimos no Mar de Timor incluiráa a cessacāõo das disposiçōes enumeradas no número 4 do seu artigo 12. ${ }^{\circ}$ e, assim, nenhuma disposição do Tratado vigoraráa após a cessação. Todas as disposiciōes do Tratado deixarão de vigorar três meses após a entrega da notificacãão de Timor-Leste.".30.

No seguimento deste Acordo, Timor-Leste notificou a Austrália, em 10 de janeiro de 2017, nos termos do art. 12. , n. ${ }^{2} 2$ do CMATS, da denúncia do CMATS que produzia efeitos daí a três meses, sendo que nenhum outro artigo se mantinha em vigor, em especial, aqueles que se referiam à eventual reentrada em vigor do Tratado CMATS no caso de efetiva

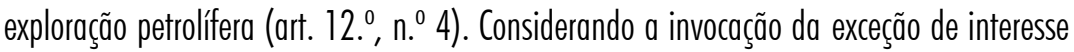
de Estado para acelerar a entrada em vigor do CMATS não é certo que a denúncia não pudesse ocorrer por consenso entre Timor-Leste e a Austrália, com uma regulamentação transitória pactualizada e que a denúncia tivesse de ser feita unilateralmente por TimorLeste. A denúncia do CMATS teve como consequências a imediata vigência das disposições dos demais Tratados em vigor sobre esta matéria, em especial, 0 TMT e 0 Acordo de Unitização de 2007, pelos quais seriam aplicadas as regras de repartiçã̃o de receitas aí previstas - que resultam da conjunnção de áreas dentro e fora da JDPA o resultado de 18\% (Timor-Leste) - 82\% (AUST), e seria necessário procurar novo fundamento legal para 0 exerćíio de poderes de autoridades timorenses (i.e. Autoridade Nacional do Petróleo Decreto- Lei n.o 20/2008, de 19 de junho), o que criou uma situação potencialmente perigosa para Timor-Leste, não fosse a expectativa, na altura, de um desenlace favorável na delimitação fronteiriça definitiva.

\footnotetext{
${ }^{30}$ № original "Joint Statement by the Governments of Timor-Leste and Australia and the Conciliation Commission constituted pursuant to Annex V of the United Nations Convention on the Law of the Sed", disponível em https://pcacases.com/web/sendAttach/2049.
} 
ULP Law Review | Revista de Direito da ULP

Vol. 13, n. .1

doi: 10.46294/ulplr13n1d3

\subsection{0 acordo de 06 de março de 2018}

0 acordo definitivo acerca da delimitação de fronteiras entre Timor-Leste e a Austrália foi assinado em 06 de março de 2018, sob os auspícios do Secretário-Geral da ONU, na sequência do processo de Conciliação Obrigatória da UNCLOS. 0 Acordo assim alcançado é uma soluçãa política de compromisso que reflete as diversas vicissitudes por que passou, desde há muitas décadas, o processo de delimitação da fronteira marítima no Mar de Timor. As posições originais das partes, bem como as soluções encontradas estão melhor descritas na figura anexa ${ }^{31}$.

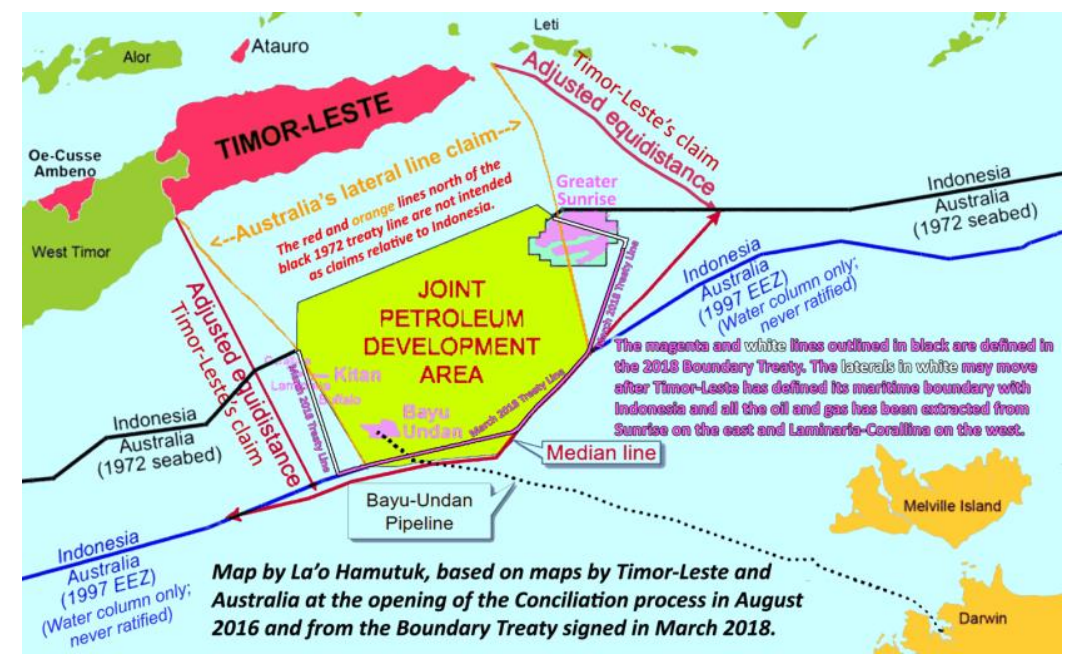

Nenhuma das partes obteve vencimento total nas suas pretensões, como, naturalmente, acontece em processos negociais complexos como este. A delimitação frontal da fronteira marítima segundo a linha mediana, no entanto, corresponde à pretensão longamente formulada pelos timorenses (e antes disso pelo Estado português, em seu nome) pelo que, assim, se reconhece a justiça dessa reclamação, mesmo que, pragmaticamente, ponderada lateralmente, em especial, cortando o campo petrolifero do "Greater Sunrise" a Oeste, para garantir uma repartição, considerada pelas partes justa (ou possível, nas circunstâncias), dos recursos naturais. Esta não foi, durante muito tempo, uma solução previsível, considerando a comparação que sempre seria feita com o acordo de 1972 entre a Austrália e a Indonésia que poderia, e pode, assim, ser posto em causa.

\footnotetext{
${ }^{31}$ Disponivel em https://www.laohamutuk.org/0i//Boundary/2018/reatyMapCenter.png, consultado pela última vez em 12 de junho de 2018.
} 
ULP Law Review | Revista de Direito da ULP

Vol. 13, n. .1

doi: 10.46294/ulplr13n1d3

As linhas de delimitação fronteiriça, previstas no art. $2 .{ }^{\circ}$ do Tratado de delimitação de fronteira entre Timor-Leste e a Austrália, são ainda provisórias, nos termos do art. 3. ${ }^{0}$, uma vez que podem ser "ajustadas", depois de esgotada a exploração comercial dos campos petrolíferos respetivos e de fixada a delimitação fronteiriça lateral entre Timor-Leste e a Indonésia - o que mais confirma a justeza da reclamação pela linha mediana durante tantos anos reclamada por Timor-Leste. Depois de regularmente ratificado pelas partes, as receitas resultantes da exploração dos recursos naturais serão totalmente afetas aos respetivos Estados, sendo ainda necessário definir os termos da exploração dos campos petrolíferos transfronteiriços. Assim, as receitas do campo de Bayu-Udan, ainda em exploração, bem como uma possível futura reexploração do campo Bufallo, passarão integralmente para 0 lado timorense, o que, facilmente, justifica a urgência na assinatura e ratificação deste Tratado por parte do Estado Timorense, mesmo em difíceis condições com um Governo com poderes limitados pela aprovação de uma moção de rejeição do seu programa de Governo, em 19 de novembro de 2017, e com a dissolução do Parlamento Nacional, em 23 de janeiro de 2018 (que também não pode deixar de ter consequências sobre o próprio Governo, que assina 0 Tratado, tanto quanto no Parlamento, que o ratifica). Em sentido inverso, as receitas do campo Laminaria-Corallina serão da parte Australiana, por este se encontrar em águas sob a sua jurisdição, sem prejuízo para a possibilidade de futuro ajuste na delimitação lateral Este para alinhar com a delimitação lateral entre Timor-Leste e a Indonésia, depois de esgotada a exploração comercial deste campo. Falta concretizar os termos da exploração conjunta do campo petrolífero transfronteiriço Greater Sunrise, o motor das negociaç̧̃̃es que culminaram na delimitação fronteiriça, já referidos no art. 7. ${ }^{\circ}$ do Tratado e no seu Anexo B, mas a carecer de decisões políiticas difíceis como a localização da exploração downstream, sem prejuízo, também aqui, para a possibilidade de futuro ajuste com a linha que vier a ser delimitada lateralmente entre Timor-Leste e a Indonésia.

Com assinatura deste Tratado, as partes prescindem de qualquer compensação pela anterior exploração conjunta dos campos petrolíferos, nos termos do art. 10. ${ }^{\circ}$ do Tratado, mesmo aqueles que agora se reconhece estarem em águas sob jurisdição do outro Estado, como os biliões de dólares já recebidos pela Austrália dos campos da Bayu-Udan - 0 que, segundo princípio da boa-fé nas relações internacionais, e mesmo o preâmbulo do Tratado, 
ULP Law Review | Revista de Direito da ULP

Vol. 13, n. .1

doi: 10.46294/ulplr13n1d3

que refere "promover o desenvolvimento económico de Timor-Leste" e ser "bons vizinhos e num espirito de cooperação e amizade (...) a fim de alcançar uma solução equitativa", não impede que o façam voluntariamente.

Após a entrada em vigor deste Tratado, nos termos do seu art. 9. ${ }^{\circ}$, cessa a vigência dos seguintes acordos: a) 0 Tratado do Mar de Timor; e b) o Acordo de Unitização internacional. 0 novo Tratado reconhece a continuidade da "Autoridade Designada", criada pelo Tratado do Mar de Timor em 2002, cujos órgãos dirigem as operações de exploração petrolífera em Timor-Leste e nos campos transfronteiriços ${ }^{32}$.

\subsection{A delimitação fronteiriça marítima entre Timor-Leste e a Indonésia}

0 processo de delimitação das fronteiras marítimas com a Indonésia está também pendente da conclusão do processo relativo à fronteira terrestre. A delimitação das fronteiras marítimas com a Indonésia é complexa, considerando a natureza dos territórios, que partilham uma ilha, incluindo um enclave e várias outras ilhas e ilhéus.

No Mar a Norte (mares de Savu e de Wetar), a definiçãa das linhas de base pela República Indonésia para a delimitação de águas arquipelágicas mereceram 0 protesto formal de Timor-Leste, em 6 de fevereiro de 2012, junto do Secretário-Geral das Nações Unidas $^{33}$. Em causa, estava a delimitação indonésia (dos pontos $101 \mathrm{E}$ (TD112A), 101F (TD1130) e 101H (TD1 13B)) que, no primeiro caso, não respeitam a delimitação mediana da separação dos mares territoriais de Timor-Leste e da Indonésia equidistante entre a ilha de Ataúro das llhas de Lirang e de Alor e, no segundo, impedem 0 acesso ao alto mar e à

\footnotetext{
${ }^{32}$ A compatibilidade da cobrança de taxas deve ser confrontada com o disposto na Lei do Fundo Petrolifero (Lei n. 9/2005, de 20 de junho) que exige que todas as receitas da exploração petrolifera sejam recolhidas no Fundo Petrolifero. Vide também o Acórdão do Tribunal de Recurso no Processo n. ${ }^{\circ} 01$-CONST-09 (AC-19-06009-P-10-CONST-09-TR) publicado no Jornal da República, Série I, n. ${ }^{\circ} 8$, 5 de agosto de 009. Disponível em htrp: $/ /$ www.tribunais.t//?q= node/ 98 fid $=6678$ sort $=$ asc\&order $=$ Display\% Oname.

${ }^{33}$ Disponivel em hitp://www.un.org/Depts/los/LEGISLATIONANDTREATIES/PDFFILES/DEPOSIT/communicationsredeposit/mzn67_2009_tls.pdf.
} 
ULP Law Review | Revista de Direito da ULP

Vol. 13, n. .1

doi: 10.46294/ulplr13n1d3

ZEE fronteira ao enclave de Oe-cusse-Ambeno, em violação do art. $47 .^{\circ}$ do n. 5 da Convenção das Nações Unidas sobre o Direito do Mar ${ }^{34}$.

Mais complicada é a delimitação fronteiriça lateral entre Timor-Leste e a Indonésia, em especial, no Mar de Timor, a Sul, que se projeta na própria questão da delimitação de fronteiras marítimas (frontal) entre Timor-Leste e a Austrália. A delimitação lateral acordada entre a Austrália e Indonésia em 1972 não põe em causa as reclamações concorrentes de Timor-Leste, pelas razões já referidas, nem será de liminarmente aceitar mesmo uma eventual cessão de posição da Indonésia por via desse Acordo com a Austrália. Mesmo a solução para jáa acordada com a Austrália na delimitação frontal é o produto da negociação política num difícil contexto, sem prejuízo de uma definitiva negociação com a Indonésia, e das consequências que possa vir a ter conforme garante o próprio Acordo entre Timor-Leste a Austrália de 06 de março de 2018. Os problemas de uma delimitação linearmente seguindo a solução da equidistância já foram apontados por MARQues ANTUNES ${ }^{35}$, apontando para um altamente prejudicial efeito de cutting-off para Timor-Leste da aplicação da regra da equidistância e foram objeto do famoso parecer de LowE ${ }^{36}$, que alimentou a negociação timorense com a Austrália, relativamente ao peso a dar a cada uma das ilhas indonésias consideradas na delimitação lateral entre Timor-Leste e a Indonésia. Esta é uma negociação que continua pendente, com grupos de trabalho transfronteiriços dedicados a esta matéria ${ }^{37}$.

\footnotetext{
${ }^{34}$ Apesar de Timor-Leste não ser, à data de apresentação deste protesto, parte da Convenção das Nações Unidas sobre o Direito do Mar, invocou a natureza consuetudinária das disposiçōes invocadas, por isso, vigentes em Direito Internacional.

${ }^{35}$ Nuno SÉrglo Marques Antunes, "Spatial Allocation of Continental Shelf Rights in the Timor Sea: Reflections on Maritime Delimitation and Joint Development" in Estudos de Direito Internacional Público, (Coimbra, Almedina, 2004), também disponível em hitps://www.laohamutuk.org/OilWeb/RDTLdocs/TSO_FS/web/nunourticle13-13.pdf, 29.

${ }^{36}$ Vaughan Lowe, Christopher Carleton e Christopher Ward, "Sobre as fronteiras marítimas de Timor-Leste", abril de 2002, disponível em http://www.petrotimor.com/img/lglopPT.pdf, 22 e ss.

${ }^{37}$ Este Tratado não tem influência direta sobre os acordos celebrados entre a Austrália e a Indonésia em matéria de delimitação de fronteira ou o tratado de limite de coluna de água (ZEE), assinado em 1997, mas ainda não ratificado. Ambos podem, no entanto, ser indiretamente impactados pelo Acordo obtido entre Timor-Leste e a Austrália em matéria de delimitação frontal de fronteiras.
} 
ULP Law Review | Revista de Direito da ULP

Vol. 13, n. .1

doi: 10.46294/ulplr13n1d3

\section{Conclusões}

0 processo de delimitação da fronteira marítima entre Timor-Leste e a Austrália é um dos mais marcantes do Direito Internacional contemporâneo, em particular, para o espaço lusófono, tendo passado desde a presença colonial portuguesa (matriz deste espaço jurídico e cultural, social e cada vez mais económico), a difíicil descolonização que se seguiu à transição democrática em Portugal, a violenta e opressiva ocupação indonésia de TimorLeste e a luta pelo exerććcio do direito à autodeterminação timorense (que juntou todos no espaço da lusofonia), até à restauração da independência e a ao esforço final de negociação que ocupou, com avanços e recuos, o mais novo Estado da Lusofonia e do século XXI.

A inesperada relevância do procedimento para a Conciliação Obrigatória é a lição mais próxima extraída do processo mais recente. Este resultado, no entanto, baseia-se na livre vontade dos participantes e, nesse sentido, só foi possível à luz do atual contexto internacional, que foi muito inteligentemente navegado pelos líderes timorenses. Não se pode menosprezar 0 peso que as razões internas em cada um dos Estados tiveram na promoção deste acordo, tanto em Timor-Leste, que em menos de um ano realizou duas eleições legislativas, como na Austrália, com a mudança de posição do principal partido da oposição. № entanto, a disponibilidade australiana para resolver esta delimitação pendente de fronteiras maríitimas deve também ser lida à luz do realinhamento da política externa americana em relação à Ásia, em particular, considerando a delimitação pendente de fronteiras maríitimas no Mar do Sul da China. Este é ainda o contexto em que as questões restantes serão negociadas, nomeadamente a definição do regime para a exploração dos campos de petróleo e gás do Greater Sunrise. A participação de Timor-Leste na reunião da iniciativa "Belt and Road", tal como no Asian Infrastructure Investment Bank, não é, neste contexto, inocente. Esta é, aliás, a melhor lição a retirar deste processo - a importância da leitura inteligente da posição geoestratégica relevante de Timor-Leste, que foi a base para a presença colonial de Portugal no século XVI, como foi para a invasão japonesa de 1941 e a invasão indonésia de 1974, mas tem sido a melhor ferramenta para o sucesso desta pequena nação de meia ilha num contexto internacional muito difícil. 